\title{
Perinatal Torsion Testis—An Enigma
}

\author{
Soumyodhriti Ghosh ${ }^{1}\left[\right.$ [ Rajendra Agarwal ${ }^{2} \cdot$ Abhijit Kundu $^{1} \cdot$ Sultan Ali Saifullah $^{3} \cdot$ Abhishek Kumar $^{1}$
}

Received: 16 June 2021 / Accepted: 28 July 2021 / Published online: 25 August 2021

(c) Dr. K C Chaudhuri Foundation 2021

Torsion of the testis in the neonatal age group is exceedingly rare. The reported incidence is around 6 per 100,000 live births [1]. Unlike torsion in older children, perinatal and neonatal torsion are extravaginal and due to lack of fixation or undue mobility of the testis $[2,3]$.

A 38 wk delivered neonate presented at the second day of life with unilateral, red scrotal swelling. Examination revealed a very tender, hard, nontransilluminant scrotal mass with no relief on scrotal elevation. Immediate color Doppler study suggested torsion of the left testis with absent vascularity. The contralateral testis was normal. The newborn underwent scrotal exploration under general anesthesia with findings of necrotic gangrenous left testis (Fig. 1). Left-sided orchiectomy with right-sided orchidopexy was performed. Postoperative period was uneventful.

Torsion of the testis is a surgical emergency with presentation time related to the chances of salvage of the affected testis. Long-term torsion results in acute ischemia leading gradually to loss of function and atrophy. Doppler sonography is increasingly used in the management of patients with suspicion $[2,3]$. The management is controversial for avascular testis with few surgeons advocating leaving the testis to atrophy. However, with advancement, neonatal general anesthesia is no longer a contraindication; hence, the authors advocate immediate surgery and contralateral fixation to preserve the chances of testicular salvage [3].

Soumyodhriti Ghosh

drsghosh.surg85@gmail.com

1 Pediatric Surgery Unit, Abhishek Child Care, Jamshedpur, Jharkhand 831001, India

2 Department of Pediatrics, The Child, Jamshedpur, Jharkhand, India

3 Department of Radiology, Dialab Diagnostics, Jamshedpur, Jharkhand, India

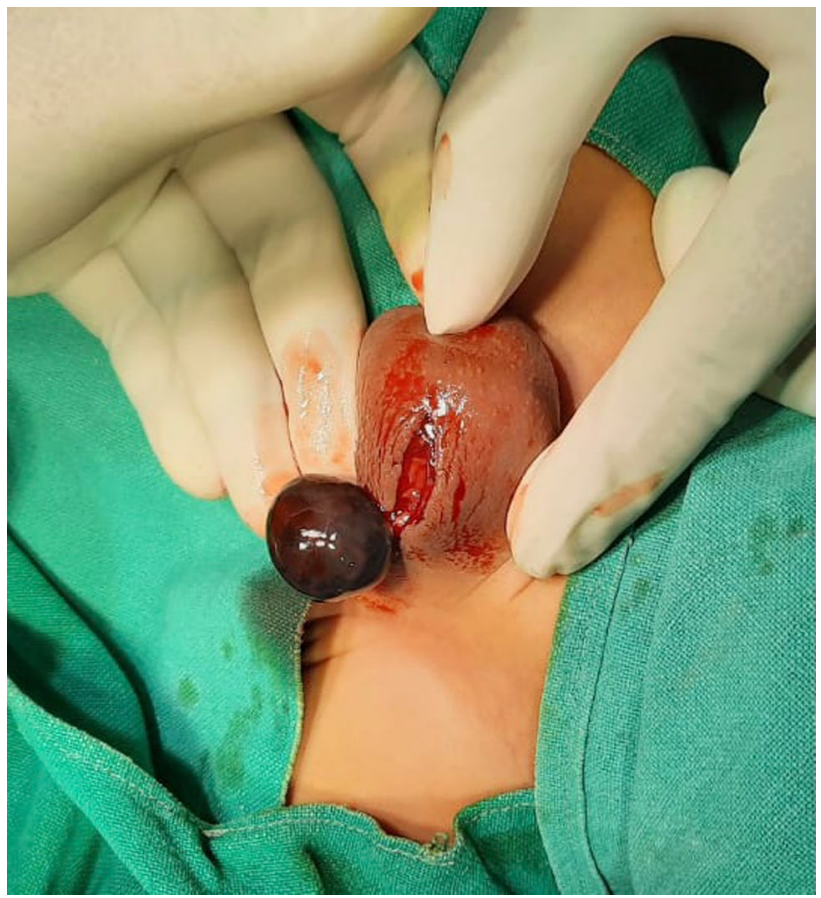

Fig. 1 Intraoperative photograph of torsion testis

\section{Declarations}

Conflict of Interest None.

\section{References}

1. Abbas TO, Ali M. Bilateral neonatal testicular torsion; hidden surgical nightmare. Front Pediatr. 2018;6:318.

2. Kylat RI. Neonatal testicular torsion: Is it time for consensus? J Clin Neonatol. 2017;6:53.

3. Bordin G, Parolini F, Morandi A, Farris G, Leva E, Torricelli M. Intravaginal testicular torsion in newborns. To fix or not to fix the contralateral testis? Pediatr Med Chir. 2013;35:225-7.

Publisher's Note Springer Nature remains neutral with regard to jurisdictional claims in published maps and institutional affiliations. 